\title{
An Outer Segment Localization Signal at the C Terminus of the Photoreceptor-Specific Retinol Dehydrogenase
}

\author{
Wenqin Luo, ${ }^{1}$ Nicholas Marsh-Armstrong, ${ }^{1,2}$ Amir Rattner, ${ }^{3}$ and Jeremy Nathans $\mathbf{s}^{1,3,4}$ \\ ${ }^{1}$ Department of Neuroscience, ${ }^{2}$ Kennedy Krieger Institute, ${ }^{3}$ Department of Molecular Biology and Genetics, and ${ }^{4}$ Department of Ophthalmology, Howard \\ Hughes Medical Institute, Johns Hopkins University School of Medicine, Baltimore, Maryland 21205
}

\begin{abstract}
Photoreceptor retinol dehydrogenase (prRDH) is a membrane-associated cytosolic protein that localizes to the outer segments (OS) of rods and cones. Here, we demonstrate that the C-terminal 16 amino acids of prRDH confer membrane association as well as cone and rod OS targeting on a linked green fluorescent protein. Membrane association in transfected 293 cells and in transgenic Xenopus photoreceptors is mediated by fatty acylation at one or more evolutionarily conserved cysteines within the prRDH C-terminal tail. In bovine OS, native prRDH is similarly acylated, and hydrolysis of this linkage releases the protein from the membrane. Efficient OS localization requires both membrane association and the prRDH sequence ... (V/I)XPX at the extreme $\mathrm{C}$ terminus, which closely resembles the C-terminal sequence that targets opsin/rhodopsin to the OS. Taken together, these data imply that the C-terminal ... (V/I)XPX sequence is a general OS localization signal that can function in the context of both integral and peripheral membrane proteins. This strategy for OS localization resembles those used for protein localization to mitochondria, peroxisomes, endosomes, and endoplasmic reticulum; in each case, a short N- or C-terminal sequence is shared among structurally diverse proteins that are targeted to the same subcellular destination.
\end{abstract}

Key words: outer segment; protein sorting; photoreceptor; palmitoylation; retinol dehydrogenase; inner segment; transgenic Xenopus

\section{Introduction}

The rod and cone photoreceptors of the vertebrate retina are highly polarized cells. Each photoreceptor cell elaborates a specialized apical cilium, referred to as an outer segment (OS). The OS is filled with a stack of flattened membrane sacs, the disc membranes. On its basal side, the photoreceptor cell forms presynaptic terminals with bipolar and horizontal cells. The OS contains the proteins that mediate phototransduction, and, as a result, its protein composition is strikingly different from that of the rest of the cell. SDS-PAGE of proteins from purified rod OS (ROS) shows that rhodopsin constitutes $\sim 80 \%$ of the protein, and the remaining $\sim 20 \%$ consists mainly of membraneassociated phototransduction components or regulators, including the heterotrimeric G-protein (transducin), cGMP phosphodiesterase, arrestin, various calcium-binding proteins, as well as integral membrane proteins such as the cGMP-gated channel, $\mathrm{Na} / \mathrm{K} / \mathrm{Ca}$ exchanger, peripherin/RDS, and the retinoid transporter ABCR (Molday, 1998).

The contents of the photoreceptor OS are subject to constant turnover throughout the life of the animal (Young, 1967). New OS proteins are synthesized within the photoreceptor cell body

Received Dec. 1, 2003; revised Jan. 23, 2004; accepted Jan. 27, 2004.

This work was supported by the Howard Hughes Medical Institute (W.L. and J.N.) and the National Institutes of Health (N.M.-A. and A.R.). We thank Phil Smallwood for preparing the GST fusion protein constructs; Rebecca Bruno and Erica Oglesby for maintaining the Xenopus facility; Maurine Linder, Randy Reed, Laurie Roman, Hui Sun, and Don Zack for advice; and Tudor Badea, Chunqiao Liu, and Tom Rotolo for helpful comments on this manuscript.

Correspondence should be addressed to Dr. Jeremy Nathans, 805 Preclinical Teaching Building, 725 North Wolfe Street, Johns Hopkins University School of Medicine, Baltimore, MD 21205. E-mail: jnathans@jhmi.edu.

DOI:10.1523/JNEUROSCI.5302-03.2004

Copyright $\odot 2004$ Society for Neuroscience $\quad 0270-6474 / 04 / 242623-10 \$ 15.00 / 0$ and transported via the connecting cilium to the base of the OS, the site of formation of the nascent OS discs. Synthesis and OS assembly at the base are matched by phagocytosis and digestion of the distal portions of the OS by retinal pigment epithelial cells. In mammalian rods, the transit time for OS contents from base to tip is $\sim 10 \mathrm{~d}$, and for the larger amphibian rods it is $\sim 30 \mathrm{~d}$. In mammals, this corresponds to a turnover rate of $\sim 5 \times 10^{6}$ rhodopsins per day per rod (Knowles and Dartnall, 1977).

The selective localization of phototransduction proteins to the OS implies the existence of a sorting system that specifically enriches for some proteins while excluding others. By analogy with other subcellular sorting systems, OS sorting must involve the recognition of one or more sequences or conformations that distinguish OS proteins from other proteins within the cell. At present, rhodopsin, an integral membrane protein, is the only OS protein for which an OS localization signal has been defined. Vertebrate rhodopsins, as well as most vertebrate cone pigments, end with the sequence... VXPX (where X can be any of a variety of amino acids) (Yokoyama, 2000). In humans, amino acid substitutions of either the conserved valine or proline or alterations that remove this region entirely cause autosomal dominant retinitis pigmentosa, a disease characterized by rod dysfunction and progressive loss of rod photoreceptors (Dryja et al., 1990, 1991; Sung et al., 1991; Rosas et al., 1994; Macke et al., 1995). In transgenic mice expressing a rhodopsin gene with a deletion of the last five amino acids, one of the retinitis pigmentosa-associated alterations, the truncated rhodopsin, accumulates in both the ROS and cell body, whereas the endogenous wild-type rhodopsin correctly localizes to the ROS (Sung et al., 1994; Concepcion et al., 2002). An analogous observation has been made in transgenic 
Xenopus with a green fluorescent protein (GFP)-tagged rhodopsin (Moritz et al., 2001). Moreover, in transgenic Xenopus, appending the last eight amino acids of rhodopsin onto a lipidanchored GFP efficiently directs the GFP fusion protein to the ROS, whereas a control GFP fusion protein lacking the rhodopsin sequence distributes to the ROS and cell body with approximately equal efficiency (Tam et al., 2000).

Here, we address the mechanism of OS localization of a peripheral membrane protein, photoreceptor-specific retinol dehydrogenase (prRDH). prRDH is the visual cycle enzyme that converts all-trans retinal, released from photoactivated rhodopsin, to all-trans retinol (Wald and Hubbard, 1949; Palczewski et al., 1994). By immunoblotting and immunostaining, prRDH is observed to be highly concentrated in the OS (Rattner et al., 2000). The experiments reported here show that the $\mathrm{C}$-terminal region of prRDH includes separate membrane attachment and OStargeting motifs, both of which are required for efficient OS localization.

\section{Materials and Methods}

DNA constructs. The backbone of each expression vector consists of pBS-SK (Stratagene, La Jolla, CA) carrying the GFP coding region (without a stop codon) inserted at the BamHI site, followed by an SV40 3' untranslated region and polyadenylation site. A $1.8 \mathrm{~kb}$ zebrafish rhodopsin or a $4.8 \mathrm{~kb}$ zebrafish UV cone opsin promotor was inserted upstream of the GFP coding region for expression in rods and cones, respectively. DNA segments coding for different $\mathrm{C}$ termini were inserted $3^{\prime}$ of the GFP coding region at the HindIII site in the polylinker. The enhanced GFP constructs with no prRDH or rhodopsin C-terminal extensions terminate with a stop codon immediately $3^{\prime}$ of the HindIII site. DNA segments coding for different $\mathrm{N}$ termini were inserted $5^{\prime}$ of the GFP coding region at the SpeI site in the polylinker. For production of transgenic frogs, the constructs were linearized at the unique NotI site $5^{\prime}$ of the promotor.

Transgenesis and GFP screening. Transgenic frogs were generated using a modification of the protocol of Kroll and Amaya (1996). In brief, Xenopus laevis sperm nuclei were mixed with $250 \mathrm{ng}$ of linearized plasmid at room temperature for $5 \mathrm{~min}, 28 \mu \mathrm{l}$ of sperm nuclei decondensor mixture (10 $\mu \mathrm{l}$ of egg extract, $0.5-1 \mathrm{U}$ of NotI, and $17 \mu \mathrm{l}$ of sperm dilution buffer) was added and incubated for an additional $15 \mathrm{~min}$, the reaction mixture was diluted to 0.2 nuclei/nl, and $\sim 10 \mathrm{nl}$ was injected per egg. Injected eggs were screened at the four- to eight-cell stage, correctly cleaving eggs were kept at $16^{\circ} \mathrm{C}$ in $0.1 \times$ Marc's modified Ringer (MMR) solution with $6 \%$ Ficoll for $24 \mathrm{hr}$, and normally developing embryos were switched to $0.1 \times$ MMR the following day. At 4-5 d postfertilization (dpf), tadpoles were screened for ocular GFP expression using a MZFLIII dissection microscope (Leica, Nussloch, Germany) equipped with epifluorescence optics and a GFP filter set.

Immunocytochemistry. At $14 \mathrm{dpf}$, transgenic tadpoles were anesthetized with $0.02 \%$ Tricaine and fixed in $4 \%$ paraformaldehyde (PFA) at room temperature for $2 \mathrm{hr}$. Eyes were excised, equilibrated in 30\% sucrose overnight at $4^{\circ} \mathrm{C}$, embedded in optimal cutting temperature medium (Tissue-Tek; Sakura, Tokyo, Japan), and frozen in a dry ice-ethanol bath. Crystat sections $(10 \mu \mathrm{m})$ were blocked in $1 \times$ PBS with $5 \%$ NGS and $0.3 \%$ Triton-X 100 and labeled at $4^{\circ} \mathrm{C}$ overnight with $0.01 \mathrm{mg} / \mathrm{ml}$ Texas Red-conjugated wheat germ agglutinin (WGA; Molecular Probes, Eugene, OR) and 1:200 mouse monoclonal anti-GFP antibody or 1:2000 rabbit anti-GFP antibody (Molecular Probes). Labeling was performed in the presence of PBS with $1 \mathrm{~mm} \mathrm{CaCl} 2,1 \mathrm{~mm} \mathrm{MgCl} 2,5 \% \mathrm{NGS}$, and $0.3 \%$ Triton X-100. Labeled sections were washed, stained with fluorescein-conjugated anti-mouse or anti-rabbit secondary antibody, mounted in Vectashield medium with 4',6-diamidino-2-phenylindole (Vector Laboratories, Burlingame, CA), and analyzed by confocal microscopy (LSM510; Zeiss, Oberkochen, Germany). At least three transgenic animals were examined for each construct (Table 1).

Cell culture and transfection. The 293 cells were used for all transfection and metabolic labeling experiments. For fluorescence microscopy, cells were transfected using Fugene 6 (Roche, Indianapolis, IN) and, $24 \mathrm{hr}$ later, fixed with $4 \%$ PFA for $20 \mathrm{~min}$ at room temperature and then processed as described above for cryostat sections.

$\left[{ }^{3} \mathrm{H}\right]$-Palmitate incorporation. Twenty-four hours after the transfection of 293 cells with a triple-myc-tagged GFP construct, the medium was changed to serum-free DMEM-F12, and after an additional $12 \mathrm{hr}$, the medium was changed to DMEM-F12 with $1 \%$ dialyzed FBS. One hour later, $300 \mu \mathrm{Ci}$ of $\left[9,10(\mathrm{n})-{ }^{3} \mathrm{H}\right]$-palmitic acid (Amersham Biosciences, Piscataway, NJ) was added per well of a 12 -well plate. The plate was incubated at $37^{\circ} \mathrm{C}$ for $1 \mathrm{hr}$, and the cells were washed with PBS and lysed in $100 \mu \mathrm{l}$ of ice-cold radioimmunoprecipitation assay (RIPA) buffer (50 mM HEPES, pH 7.4, $150 \mathrm{~mm} \mathrm{NaCl}, 1 \%$ NP-40, 0.5\% deoxycholate, $0.1 \%$ SDS, $2.5 \mathrm{~mm}_{\mathrm{MgCl}_{2}}$, and $1 \mathrm{~mm}$ EDTA) with protease inhibitors. Detergent-insoluble material was removed by centrifugation at $13,000 \times$ $g$ at $4^{\circ} \mathrm{C}$ for $5 \mathrm{~min}$, the supernatants were added to $10 \mu \mathrm{l}$ of protein $\mathrm{A} / \mathrm{G}$ beads (Pierce, Rockford, IL) prebound with $\sim 5 \mu \mathrm{g}$ of anti-Myc monoclonal antibody $(\mathrm{mAb})$, and the samples were rotated at $4^{\circ} \mathrm{C}$ for $3 \mathrm{hr}$. The beads were washed with RIPA buffer, resuspended in $15 \mu \mathrm{l}$ of $2 \times$ SDS sample buffer without DTT, heated at $55^{\circ} \mathrm{C}$ for $5 \mathrm{~min}$, and the eluted proteins resolved by SDS/PAGE on a $15 \%$ gel. Coomassie blue-stained gels were infiltrated with Amplify (Amersham Biosciences) supplemented with 5\% glycerol, dried, and exposed to film for 2-4 weeks.

Hydroxylamine treatment of Xenopus and bovine OS. A founder male frog carrying the pWL86 transgene was mated to wild-type females and, from the progeny showing ocular GFP fluorescence retinas, were dissected at $\sim 14 \mathrm{dpf}$. OS were purified by sucrose flotation (Papermaster, 1982), treated with PBS, PBS containing $1 \%$ Triton-X 100, or $1 \mathrm{M}$ hydroxylamine ( $\mathrm{pH}$ 7.5; Alfa Aesar, Ward Hill, MA) at room temperature for 1 $\mathrm{hr}$, and then divided into supernatant and pellet fractions by centrifugation at $25,000 \times g$ at $4^{\circ} \mathrm{C}$ for $30 \mathrm{~min}$. OS proteins were analyzed by SDS/PAGE on a $15 \%$ gel followed by immunoblotting with anti-GFP antibodies. For hydroxylamine treatment of bovine OS, purified OS ( $\mathrm{Pa}-$ permaster, 1982) were treated with either PBS or $1 \mathrm{M}$ hydroxylamine ( $\mathrm{pH}$ 7.5 ) at room temperature for $5 \mathrm{hr}$ and then divided into supernatant and pellet fractions as described above. The samples were heated in SDS sample buffer at either 55 or $100^{\circ} \mathrm{C}$ either with or without $20 \mathrm{~mm}$ DTT before SDS-PAGE.

\section{Results}

\section{A conserved C-terminal extension in prRDH mediates membrane association}

prRDH is a member of the large family of short-chain dehydrogenases (SDRs) (Rattner et al., 2000). The globular catalytic domain of the SDRs has been defined by the high-resolution crystal structure of a complex between 17- $\beta$-hydroxysterol dehydrogenase-1 and NADPH (Sawicki et al., 1999) and corresponds to the first $\sim 290$ amino acids in the prRDH sequence. Among SDR family members, the catalytic domain generally behaves as a water-soluble polypeptide. As first noted by Rattner et al. (2000), bovine and human prRDH contain a C-terminal extension of $\sim 20$ amino acids beyond the catalytic domain that is not found in other SDR family members. Figure $1 A$ shows that this C-terminal extension is also present in the predicted mouse, zebrafish, and pufferfish prRDH sequences, the only other prRDH sequences known at present. Most interestingly, among these five prRDH sequences, the four amino acids at the extreme $\mathrm{C}$ terminus conform to the consensus ... (V/I)XPX, reminiscent of the C-terminal consensus . . VXPX found in most vertebrate visual pigments. Despite the very different structures of these two classes of proteins, their similarity in this region suggests that the OS localization of prRDH might be directed by the ... (V/I)XPX motif in the same way that ROS localization of rhodopsin is directed by the ... VXPX motif.

The alignment of prRDH sequences also shows three conserved cysteines within 16 amino acids of the $\mathrm{C}$ terminus: two cysteines closest to the $\mathrm{C}$ terminus are absolutely conserved and one cysteine further from the $\mathrm{C}$ terminus is present in four of the 
Table 1. Summary of GFP constructs

\begin{tabular}{|c|c|c|c|c|c|c|}
\hline Constructs & $\begin{array}{l}\text { Expressing } \\
\text { cell type }\end{array}$ & Protein sequence & Membrane association & Localization & $\begin{array}{c}\text { Number of } \\
\text { animals examined }\end{array}$ & Figure number \\
\hline pWL5 & 293 & GFP-LRCLACSCFRTPVWPR & yes & plasma membrane & & $1 B, C$ \\
\hline pWL6 & 293 & GFP-LRALAASAFRTPVWPR & no & cytosol & & $1 B, C$ \\
\hline pWL30 & rod & GFP & no & OS $<<$ IS, CB & 6 & $2 A$ \\
\hline pWL86 & rod & GFP-LRCLACSCFRTPVWPR & yes & OS $\gg$ IS, CB & 12 & $2 B, E$ \\
\hline pWL31 & cone & GFP & no & OS $\ll<$ IS, CB & 3 & $2 C$ \\
\hline pWL132 & cone & GFP-LRCLACSCFRTPVWPR & yes & OS & 8 & $2 D$ \\
\hline pWL87 & rod & GFP-LRALAASAFRTPVWPR & no & OS $\ll<$ IS, CB & 5 & $3 A$ \\
\hline pWL100 & rod & GFP-LRCLACSAFRTPVWPR & yes/no & $\mathrm{OS}<\mathrm{IS}, \mathrm{CB}$ & 5 & $3 B$ \\
\hline pWL98 & rod & GFP-LRALACSCFRTPVWPR & yes & OS, IS, CB & 4 & $3 C$ \\
\hline pWL99 & rod & GFP-LRCLAASCFRTPVWPR & yes & OS, IS, CB & 7 & $3 D$ \\
\hline pWL102 & rod & GFP-LRCLACSCFRTP & yes & $\mathrm{OS}>\mathrm{IS}, \mathrm{CB}$ & 3 & $4 A$ \\
\hline pWL167 & rod & GFP-LRCLACSCFRTPAWWAR & yes & base of OS, IS, CB & 6 & 4 \\
\hline pWL127 & rod & MGCINSKRKD-GFP- & yes & OS, IS, CB & 6 & $5 A$ \\
\hline pWL142 & rod & MGCINSKRKD-GFP- FRTPVWPR & yes & $\mathrm{OS} \gg \mathrm{IS}, \mathrm{CB}$ & 5 & $5 B$ \\
\hline pWL141 & rod & MGCINSKRKD-GFP-SSSQVSPA & yes & $\mathrm{OS}>\mathrm{IS}, \mathrm{CB}$ & 5 & $5 C$ \\
\hline pWL129 & rod & MLCCMRRTKQ- GFP- & yes & OS, IS, CB & 9 & $5 D$ \\
\hline pWL144 & rod & MLCCMRRTKQ- GFP-FRTPVWPR & yes & OS, IS, CB & 10 & $5 E$ \\
\hline pWL143 & rod & MLCCMRRTKQ- GFP-SSSQVSPA & yes & OS, IS, CB & 8 & $5 F$ \\
\hline pWL158 & rod & MLCCLCMRRTKQ- GFP- & yes & OS $>$ IS, $\mathrm{CB}$ & 3 & $6 A$ \\
\hline pWL154 & rod & MLCCLCMRRTKQ-GFP-FRTPVWPR & yes & $\mathrm{OS}>\mathrm{IS}, \mathrm{CB}$ & 3 & $6 B$ \\
\hline pWL153 & rod & MLCCLCMRRTKQ- GFP-SSSQVSPA & yes & $\mathrm{OS}>\mathrm{IS}, \mathrm{CB}$ & 3 & $6 C$ \\
\hline pWL155 & rod & MLCCLCCMRRTKQ- GFP- & yes & $\mathrm{OS}>\mathrm{IS}, \mathrm{CB}$ & 4 & $6 D$ \\
\hline pWL157 & rod & MLCCLCCMRRTKQ-GFP-FRTPVWPR & yes & OS & 10 & $6 E$ \\
\hline pWL156 & rod & MLCCLCCMRRTKQ- GFP- SSSQVSPA & yes & $\mathrm{OS} \gg \mathrm{IS}$ and $\mathrm{CB}$ & 2 & $6 F$ \\
\hline
\end{tabular}

OS, Outer segment; IS, inner segment; CB, cell body and synapse. The putative lipid modification sites of proteins are indicated in red, GFP is indicated in green, the C-terminal 8 amino acids of bovine prRDH are indicated in blue, and the $\mathrm{C}$-terminal 8 amino acids of Xenopus rhodopsin are indicated in magenta.

five prRDH sequences (Fig. $1 A$ ). This suggests the possibility that the strong membrane association observed for prRDH (Lion et al., 1975; Blaner and Churchich, 1980; Nicotra and Livrea, 1982; Ishiguro et al., 1991; Palczewski et al., 1994; Rattner et al., 2000) might be mediated by the conserved cysteines near the $\mathrm{C}$ terminus, possibly via palmitoylation, a mode of membrane association commonly observed among peripheral membrane proteins (El-Husseini and Bredt, 2002).

As an initial test of this idea, we compared the subcellular distribution in transfected 293 cells of GFP, a GFP fusion to the C-terminal 16 amino acids of prRDH (coded by pWL5), or an otherwise identical GFP fusion protein in which the three conserved prRDH cysteines were all mutated to alanine (coded by pWL6). (Plasmid names and structures are listed in Table 1; all of the prRDH constructs described here used bovine prRDH se- quences, and, therefore, any reference to prRDH without a species designation will indicate the bovine sequence, unless noted otherwise.) As seen in Figure $1 B$, the 16 C-terminal amino acids of prRDH efficiently localize GFP to the plasma membrane in 293 cells, and this localization is lost when all three cysteines are mutated. The nuclear localization of a fraction of the pWL6 fusion protein further suggests that mutation of the three C-terminal cysteines primarily or completely eliminates any association with internal membranes, although we note that GFP without any C-terminal extension shows even greater nuclear localization.

To directly test the idea that one or more of the three C-terminal cysteines might be palmitoylated, 293 cells transfected with N-terminal triple-myc-tagged derivatives of pWL5 or pWL6 were labeled for $1 \mathrm{hr}$ with $\left[9,10(\mathrm{n})-{ }^{3} \mathrm{H}\right]$ palmitic acid, and 


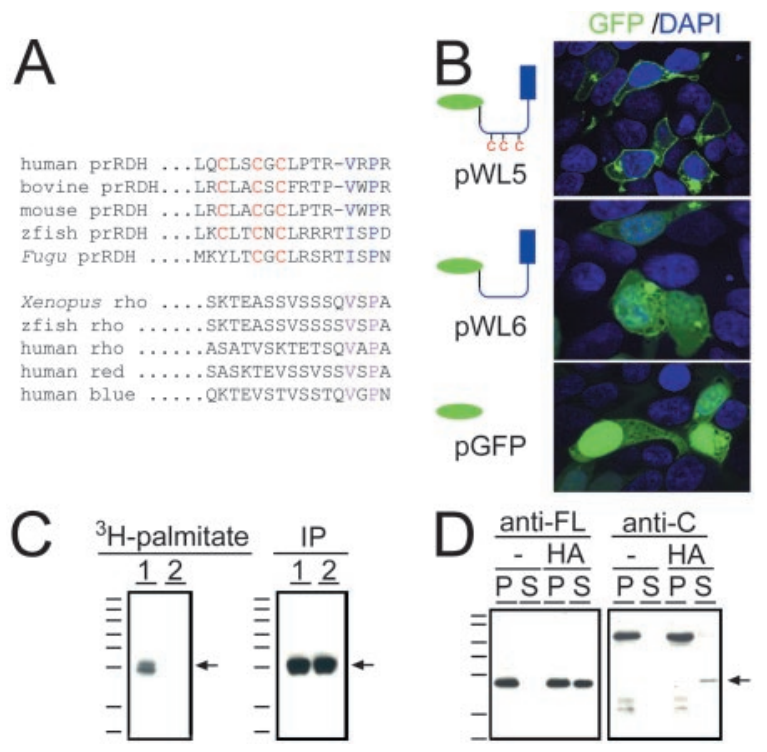

Figure 1. The C-terminal 16 amino acids of prRDH contain a membrane association signal. $A$, Alignment of the $C$ termini of vertebrate prRDH and rod and cone pigments. Most vertebrate visual pigments and all prRDH sequences terminate with the ... (V/I)XPX motif. Cysteines are shown in red, and the residues at -2 and -4 are colored. $B$, Shown are 293 cells transfected with GFP fusion proteins containing either a 16 amino acid C-terminal extension from prRDH (top), the same extension but with all three cysteines mutated to alanine (center), or no C-terminal extension (bottom). Nuclei were stained with 4',6-diamidino-2-phenylindole. In these and all subsequent diagrams of GFP fusion proteins, the GFP portion is represented by a green oval with the $\mathrm{N}$ terminus to the left and the $\mathrm{C}$ terminus to the right. $\mathrm{C},{ }^{3} \mathrm{H}$-palmitate labeling of 293 cells transfected with triple-myc-tagged pWL5 (lane 1) or pWL6 (lane 2). GFP fusion proteins were immunoprecipitated with anti-myc $m A b$ for analysis of ${ }^{3} \mathrm{H}$-palmitate incorporation (left). Anti-GFP immunoblotting shows that the two GFP fusion proteins accumulate to comparable levels (right). The film for detecting the ${ }^{3} \mathrm{H}$ label was exposed for 2 weeks. Close inspection shows two resolvable ${ }^{3} \mathrm{H}$-labeled bands, suggesting that at least two cysteines can be modified. The arrows indicate the GFP fusion proteins. Molecular mass standards (at left) from top to bottom, are 184, 120,87, 64, 52, 39, 26, and $21 \mathrm{kDa}$. D. Hydroxylamine treatment releases prRDH from bovine $0 S$ membranes and reveals a C-terminal epitope. Immunoblots were probed with antibodies directed against amino acids 5-312 of bovine prRDH expressed in Escherichia coli (left; anti-FL) or a (-terminal nine amino acid peptide from bovine prRDH (right; anti-C) (Rattner et al., 2000). OS membranes were separated into pellet (P) and supernatant (S) fractions after a $5 \mathrm{hr}$ incubation at room temperature with PBS $(-)$ or 1 m hydroxylamine (HA) and heated to $55^{\circ} \mathrm{C}$ in SDS sample buffer with $20 \mathrm{~mm}$ DTT. The arrow indicates prRDH. Several proteins associated with OS membranes are observed to cross-react with the anti-prRDH C-terminal peptide antibody. Rhodopsin was not released into the supernatant with hydroxylamine treatment, as judged by Coomassie blue staining (data not shown). Molecular mass standards (at left) from top to bottom, are 110, 79, 62, 48, 37, 24, and 19 kDa.

the incorporation of ${ }^{3} \mathrm{H}$ into the GFP fusion proteins was analyzed by immunoprecipitation with an anti-myc mAb. Figure $1 C$ shows that ${ }^{3} \mathrm{H}$-palmitate is incorporated into the fusion protein carrying the three C-terminal cysteines (myc-pWL5; lane 1) but not the fusion protein in which these cysteines have been mutated (myc-pWL6; lane 2), consistent with the hypothesis that palmitoylation of one or more of the cysteines near the $\mathrm{C}$ terminus of prRDH mediates membrane association. Interestingly, there appear to be two distinct ${ }^{3} \mathrm{H}$-labeled species, suggestive of heterogeneity in the palmitoylation site(s) or the number of palmitates added.

Native prRDH has not yet been isolated in sufficiently pure form to permit direct chemical analysis of its covalent modification(s). We, therefore, performed an indirect test of fatty acylation and its potential role in membrane association based on the lability of the thioester linkage between cysteine and a fatty acid to hydroxylamine cleavage (Linder et al., 1995; Jackson and Magee,
2002). Hydroxylamine treatment of bovine OS led to the conversion of approximately half of the prRDH from a membraneassociated form to a soluble form, as determined by immunoblotting with antibodies raised to the full-length protein (Fig. $1 D$, left). Interestingly, the soluble form of prRDH, generated by hydroxylamine treatment, was specifically recognized by an antipeptide antibody directed against the C-terminal nine amino acids of bovine prRDH (Fig. $1 D$, right). This peptide immunogen includes the most $\mathrm{C}$ terminal of the three cysteines (Rattner et al., 2000). We ascribe the absence of antibody binding by membraneassociated prRDH and the appearance of binding by hydroxylamine-treated and solubilized prRDH to the release of a thioester adduct that sterically hinders binding by the anti-Cterminal peptide antibody. This interpretation is further supported by the observation that binding of prRDH to the anti-Cterminal peptide antibody appears after incubation of the pelletable prRDH (after the hydroxylamine treatment described above) at $100^{\circ} \mathrm{C}$ in SDS sample buffer containing $20 \mathrm{~mm}$ DTT but not by incubation at $100^{\circ} \mathrm{C}$ in the absence of reducing agent (data not shown), consistent with the known lability of thioester linkages to DTT at an elevated temperature (Jackson and Magee, 2002). We note that the thioether linkage associated with protein prenylation is not labile to hydroxylamine treatment, arguing against prenylation of the C-terminal cysteines as a cause of membrane association.

\section{Function of the $\mathrm{C}$ terminus of prRDH in transgenic Xenopus photoreceptors}

To test the hypothesized function of the prRDH C terminus in photoreceptors, we have used transgenic Xenopus as described by Knox et al. (1998) and Moritz et al. (1999). With this system, large numbers of independently derived transgenic tadpoles can be produced and their fully developed retinas analyzed at $\sim 2$ weeks of age. The large size of Xenopus photoreceptors facilitates an accurate assignment of subcellular localization by confocal microscopy. We note that a Xenopus prRDH homolog has not yet been identified, and the antibodies raised against mammalian prRDH do not appear to cross-react with Xenopus retinas. However, the existence of a zebrafish prRDH ortholog strongly suggests that prRDH also exists in Xenopus.

In an initial series of experiments, we asked whether the subcellular distribution of GFP was altered by appending the last 16 amino acids of bovine prRDH to its $\mathrm{C}$ terminus. As seen in Figure $2 A$, expression of GFP under the control of the zebrafish rhodopsin promotor leads to GFP accumulation throughout the rod photoreceptor cell body with minimal accumulation in the ROS. [In this and all subsequent images of transgenic photoreceptors, GFP is visualized with a fluorescein-conjugated secondary antibody (green), and the ROS membranes and rod cell plasma membrane are visualized with Texas Red-conjugated WGA (red); in each panel, the OS occupy the top half of the image, and the inner segment (IS)-OS junction in one representative cell is marked by a white arrowhead.] In contrast, appending the C-terminal 16 amino acids from bovine prRDH onto GFP leads to efficient ROS localization (Fig. 2B). A similar result was obtained when the same pair of proteins was expressed in cone photoreceptors under the control of a zebrafish UV cone opsin promotor (Fig. $2 C, D)$. Within transgenic rods, but not cones, the GFP fusion protein localizes preferentially to the basal region of the OS. This localization within the ROS does not appear to reflect a delay in the timing of transgene expression, because transgenic tadpoles carrying the same promotor driving a rhodopsin-GFP fusion show no gradient in GFP fluorescence along the length of the 


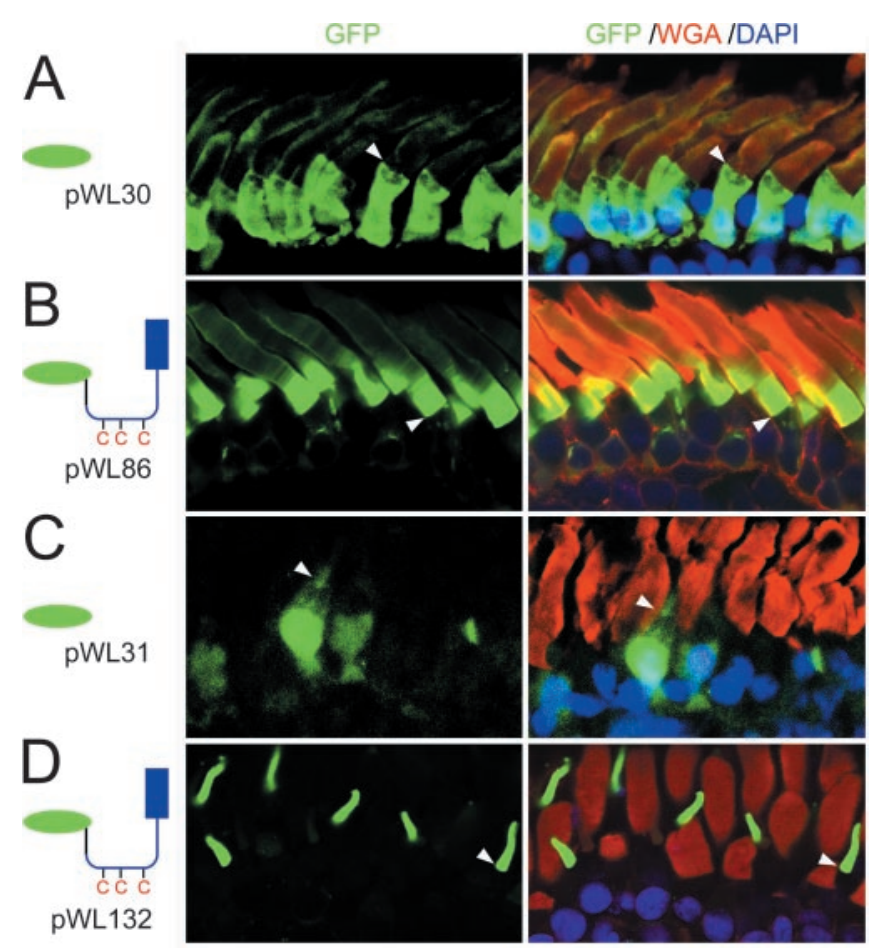

Figure 2. The C-terminal 16 amino acids of prRDH targets GFP to the $O S$ of both rods and cones in transgenic Xenopus. A, C, GFP without a C-terminal extension localizes predominantly to the cell bodies of rods $(A)$ and cones (C) B, D, GFP fused to the C-terminal 16 amino acids of prRDH localizes predominantly to the $O S$ in rods $(B)$ and cones $(D)$. Left, GFP (green). Right, Overlay of GFP, ROS labeled with Texas Red-conjugated WGA (red), and 4',6-diamidino-2phenylindole (blue). The arrowheads in this and all subsequent figures mark the IS-0S junction.

ROS (data not shown). This phenomenon is discussed further below.

The role of the three C-terminal cysteines in transgenic tadpoles was tested by substituting all three simultaneously with alanine in the context of the GFP-prRDH C-terminal fusion protein coded by pWL86. As seen in Figure 3A, the GFP fusion protein lacking all three cysteines (coded by pWL87) localizes predominantly to the cell body where it appears not to be strongly associated with cytosolic membranes, as judged by anti-GFP immunostaining in both the cytosol and nucleus. Mutants of the GFP-prRDH C-terminal fusion protein that carry single cysteine-to-alanine substitutions at each of the three C-terminal cysteines show a modest diminution in the efficiency of ROS localization if either the first or second cysteines are mutated (Fig. $3 C, D)$ and a dramatic loss of ROS localization if the most C-terminal cysteine is mutated (Fig. 3B). Mutation of the most C-terminal cysteine also leads to appreciable GFP localization in the nucleus.

The relatively large size of a tadpole and the small quantity of GFP fusion protein per retina preclude a direct test of palmitoylation by in vivo labeling with ${ }^{3} \mathrm{H}$-palmitate. However, the indirect test described above, which is based on the lability of the thioester linkage to hydroxylamine cleavage, requires only a quantity of protein sufficient for detection by immunoblotting. To explore this approach, ROS purified from a stable line of transgenic tadpoles expressing the GFP fusion coded by pWL86 were treated with PBS, PBS with $1 \%$ Triton-X 100, or $1 \mathrm{~m}$ hydroxylamine, and the effect on the GFP fusion protein was monitored by SDSPAGE. As seen in Figure 3E, Triton-X 100 and hydroxylamine efficiently converted the GFP fusion protein from a pelletable form to a soluble form. In the case of Triton-X 100, this is the

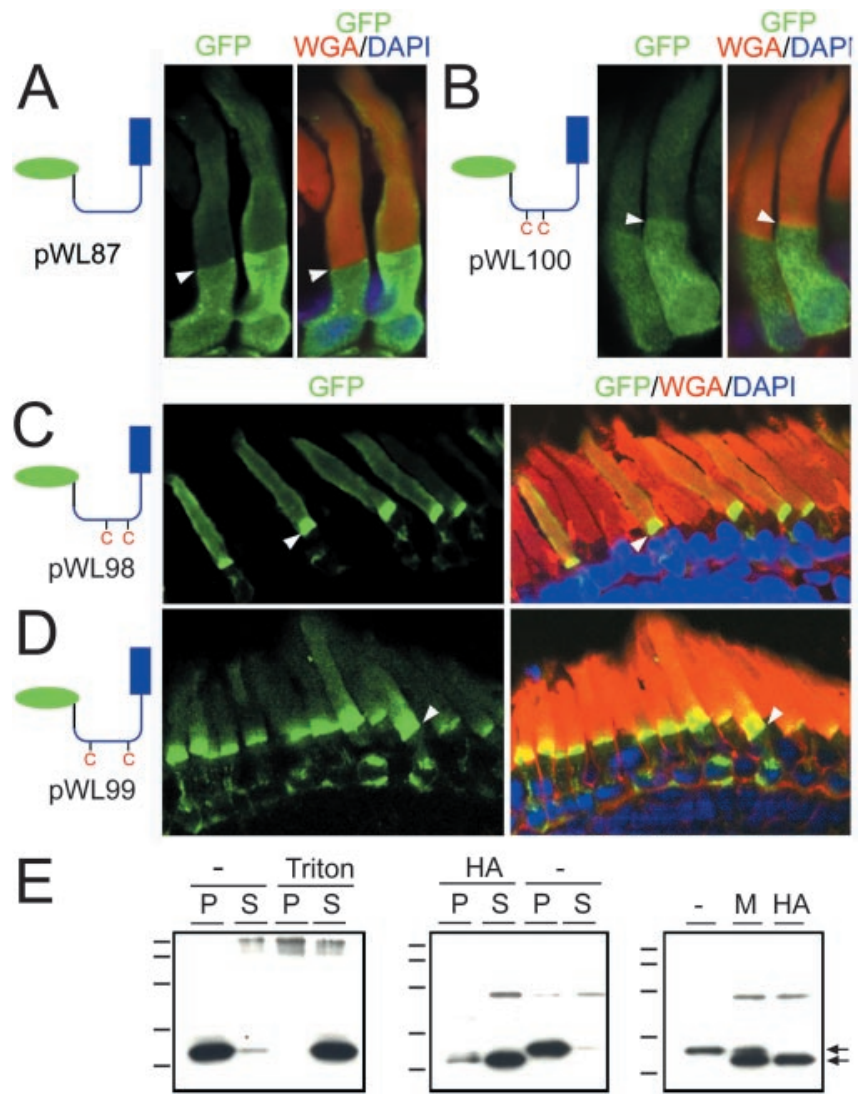

Figure 3. Role of the C-terminal cysteines of prRDH in ROS localization and membrane association. $A-D$, Subcellular localization in transgenic Xenopus rods of GFP fusion proteins carrying mutated derivatives of the $\mathrm{C}$-terminal 16 amino acids of prRDH. The three prRDH cysteines were mutated to alanine together $(A)$ or individually $(B-D)$. $E$, Membrane association and electrophoretic mobility of the pWL86 -GFP fusion protein from F1 tadpoles. Left and center, Purified ROS were treated with PBS (-), with PBS containing $1 \%$ Triton-X 100 (Triton), or with $1 \mathrm{~m}$ hydroxylamine $(\mathrm{HA})$ and divided into supernatant $(\mathrm{S})$ and pellet $(\mathrm{P})$ fractions by centrifugation [confirmed by Coomassie staining of rhodopsin (data not shown)]. Right, Mixing the untreated and hydroxylamine-treated samples (M) shows that the shift in apparent molecular mass attributable to hydroxylamine treatment is not an electrophoretic artifact. The arrows at right indicate the GFP fusion protein before and after hydroxylamine treatment. Rhodopsin was not released into the supernatant with hydroxylamine treatment, as judged by Coomassie blue staining (data not shown). Molecular mass standards (at left) from top to bottom, are 64,52,39, 26 , and $21 \mathrm{kDa}$.

expected affect of solubilizing the ROS membranes, and the release of the GFP fusion is unaccompanied by a change in its apparent molecular mass. In contrast, hydroxylamine treatment also produces a decrement in apparent molecular mass of $\sim 3$ $\mathrm{kDa}$, consistent with the cleavage of one or more lipid adducts. The failure to see a similar decrement in apparent molecular mass on hydroxylamine treatment of native bovine prRDH (Fig. 2D) may reflect a context dependence of the effect of fatty acylation on relative protein mobility in SDS-PAGE, consistent with previous observations on the different electrophoretic effects of hydroxylamine-mediated release of palmitate from G-protein $\alpha$ subunits, RGS4, and SNAP-25 (Linder et al., 1995; Gonzolo and Linder, 1998; Srinavasa et al., 1998).

As described above, the thioether linkage associated with protein prenylation is not labile to hydroxylamine treatment, arguing against prenylation of the C-terminal cysteines. In keeping with this inference, in vitro incubation of a combination of bovine retina extracts enriched for prenyl transferase activity [prepared as described by Reiss et al. (1990) and Qin et al. (1992)], 
${ }^{3} \mathrm{H}$-labeled geranylgeranylpyrophosphate or farnesylpyrophosphate, and purified GST fusion proteins carrying the C-terminal 16 amino acids of prRDH or the C-terminal 10 amino acids of the $\alpha$ or $\beta$ subunits of bovine rod photoreceptor cGMP phosphodiesterase led to efficient geranylgeranylation of the phosphodiesterase $\beta \mathrm{C}$ terminus and efficient farnesylation of the phosphodiesterase $\alpha \mathrm{C}$ terminus, as expected (Qin et al., 1992; Anan et al., 1992), but no prenylation of the prRDH C terminus with either ${ }^{3} \mathrm{H}$-substrate (data not shown).

Taken together, the data in Figures 1-3 indicate that one or more of the three C-terminal cysteines within the GFP-prRDH fusion protein is fatty acylated in both 293 cells and photoreceptors, that this fatty acylation mediates membrane association, that a similar fatty acylation mediates membrane association of native prRDH in bovine OS, and that in both rod and cone photoreceptors this modification is required for efficient OS localization of the GFP fusion protein. The most important of the three cysteines for ROS localization (the most C-terminal of the three) is one of the two cysteines that are absolutely conserved among the five known prRDH sequences (Fig. 1A). These data complement and extend those of Tam et al. (2000), who also inferred an important role for membrane association based on their analysis of GFP-rhodopsin fusion proteins.

\section{The role of the ... (V/I)XPX motif}

The role of the four amino acids at the extreme $\mathrm{C}$ terminus of prRDH was first tested by constructing a truncation mutant in which these residues were eliminated from the GFP-prRDH C-terminal fusion protein (coded by pWL102). With this construct, the majority of the GFP fusion protein localizes to the ROS, where it is uniformly distributed along the length of the OS. However, relative to the nontruncated parent construct (coded by pWL86), a larger fraction of the GFP remains within the cell body (compare Figs. $2 B$ and $4 A$ ). As a second and more refined test of the role of the extreme $\mathrm{C}$ terminus, the conserved valine at position -4 and proline at position -2 were simultaneously $\mathrm{mu}-$ tated to alanine (coded by pWL167). As seen in Figure 4B, the double substitution mutant shows considerably greater localization to the cell body, and within the ROS it localizes preferentially to the base. Both of these C-terminal mutants appear to be mainly membrane associated, as judged by their efficient exclusion from the nucleus. The greater severity of the ROS localization defect with alanine substitution at positions -2 and -4 compared with that seen after deletion of the C-terminal four residues is surprising and could be related to the massive accumulation of vesicular material seen at the IS-OS junction in P347S transgenic mice, which may represent misrouting of mutant rhodopsin during transport to the OS (Li et al., 1996). Figure $4 B$ shows that the pWL167 fusion protein has no apparent effect on the localization of the endogenous Xenopus rhodopsin, implying that the inefficient ROS localization of the fusion protein does not reflect a general inhibition or saturation of the OS sorting machinery.

\section{OS localization and the efficiency of membrane association}

The experiments described above suggest that membrane association and a specificity imparted by the extreme $\mathrm{C}$ terminus function together to determine OS versus cell body localization as well as the distribution of the fusion protein along the length of the ROS. To explore the relationship between OS localization efficiency and the number and type of lipidation sites, the location of lipidation sites within the protein, and the C-terminal ... (V/ I)XPX motif, we determined the subcellular localization of GFP fusion proteins with either: (1) the C-terminal eight amino acids

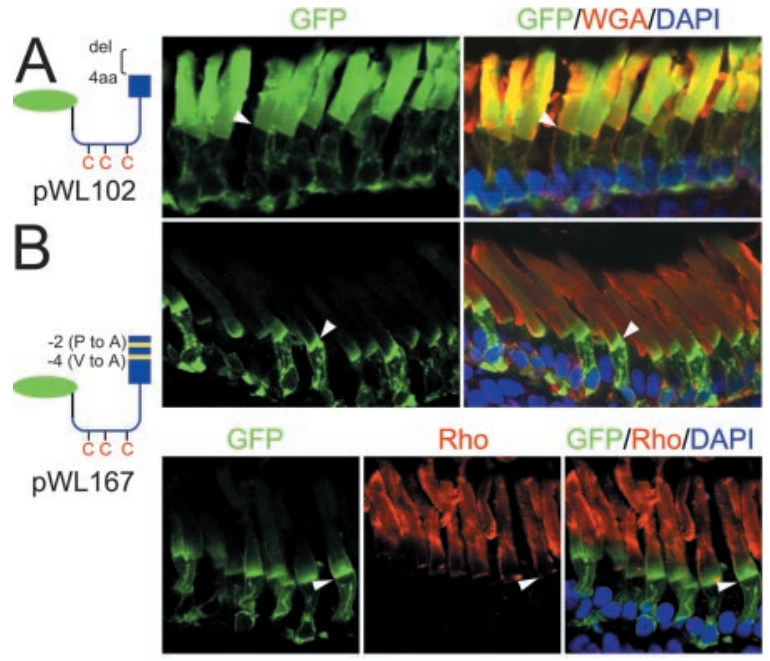

Figure 4. The ... VXPX motif at the C terminus of prRDH facilitates ROS localization of GFP fusion proteins. A, Deletion of the four C-terminal amino acids from the GFP-prRDH C-terminal fusion produces only a small decrease in the efficiency of ROS localization (compare with Fig. $2 B$ ). $B$, Mutation of the conserved valine at -4 and proline at -2 to alanine results in localization of the majority of the GFP fusion protein to the IS, cell body, and base of the ROS. Bottom center, Endogenous rhodopsin (stained with mAb 1D4; red) is not mislocalized in rods expressing pWL167. We note that the high rhodopsin concentration in the ROS leads to efficient capture of the $1 \mathrm{D} 4 \mathrm{mAb}$ near the ROS surface with inefficient immunostaining in the ROS interior.

of prRDH; (2) the C-terminal eight amino acids of rhodopsin; or (3) no C-terminal addition, in the context of an N-terminal extension with either two, three, or four potential sites of lipidation. The N-terminal extensions were derived from the $\mathrm{N}$-terminal 10 amino acids of Lyn kinase or GAP43 (Resh, 1999). The native Lyn kinase sequence, MGCINSKRKD, has a myristoylation site at glycine 2 and a palmitoylation site at cysteine 3 . The native GAP43 sequence, MLCCMRRTKQ, has two palmitoylation sites at cysteines 3 and 4 .

Figure 5 shows a comparison of an initial group of six GFP constructs in which each of the two native $\mathrm{N}$ termini (with two lipidation sites) are placed in combination with each of the three C termini described above. Although the Lyn kinase N-terminal extension shows a modest enhancement of ROS localization of GFP when the C-terminal eight amino acids from prRDH or rhodopsin are appended (Fig. 5, compare $A$ with $B$ and $C$ ), the GAP43 N-terminal extension confers little or no increase in ROS localization with the prRDH or rhodopsin $\mathrm{C}$ termini (compare $5 \mathrm{D}$ to $5 \mathrm{E}$ and $5 \mathrm{~F}$ ). These data indicate that a myristate/palmitate pair is more effective than a palmitate/palmitate pair in directing OS localization.

The inefficient OS localization of the GAP43-GFP fusions led us to ask whether progressively increasing the strength of membrane association might promote increased ROS localization and, if so, whether that localization would be dependent on the presence of a ... (V/I)XPX motif at the $\mathrm{C}$ terminus. To effect an increase in membrane association, one or two additional cysteines were added to the GAP43 N-terminal extension by insertion after the fifth amino acid (coded by pWL153-158). Figure 6 shows that these sequence changes lead to a stepwise increase in ROS localization of GFP that depends in part on the presence of the C-terminal eight amino acids of prRDH or rhodopsin. In particular, GFP fusions that carry four cysteines in the $\mathrm{N}$-terminal extension together with the rhodopsin or prRDH C terminus show highly efficient ROS localization (Fig. 6, compare $D$ with $E$ and $F$ ). There is also a stepwise increase in the unifor- 


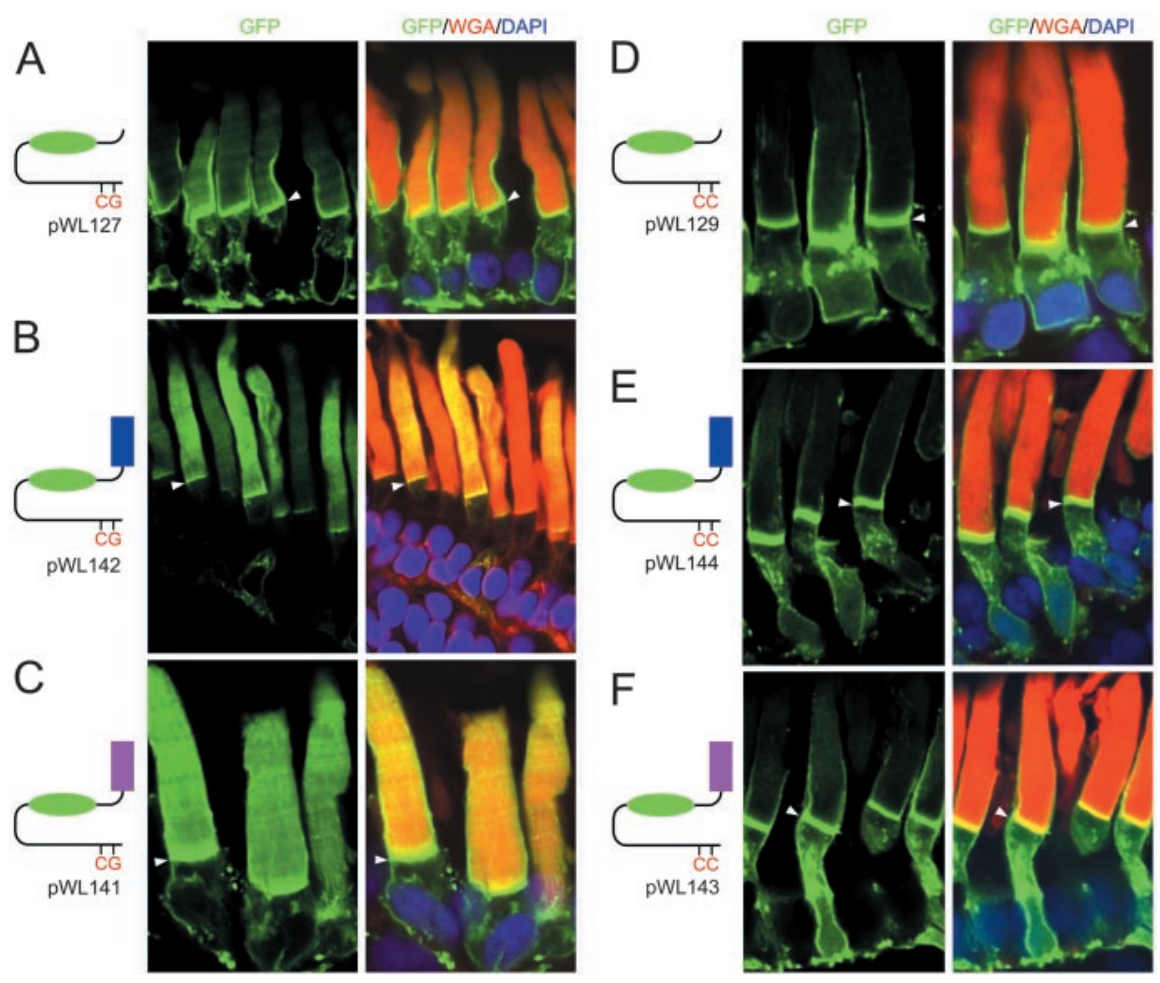

Figure 5. ROS localization of GFP fusions with N-terminal membrane association domains and C-terminal ... (V/I)XPX motifs. $A-C$, An N-terminal extension derived from Lyn kinase and containing a myristoylation site and a palmitoylation site ( $G$ and $C$, respectively) fused with GFP $(A)$ or with GFP carrying the eight C-terminal amino acids from prRDH $(B)$ or rhodopsin $(C)$. D-F, $A n$ $\mathrm{N}$-terminal extension derived from GAP43 and containing two palmitoylation sites (each represented by $C$ ) fused with GFP $(D)$ or with GFP carrying the eight C-terminal amino acids from $\operatorname{prRDH}(E)$ or rhodopsin $(F)$. In $D-F$, the fusion protein accumulates most prominently at the base of the ROS. The addition of the prRDH or Xenopus rhodopsin C terminus to the Lyn kinase-GFP fusion leads to an increase in the relative efficiency of ROS localization $(A$, compare $B, C$, whereas the addition of the same segment to the GAP43-GFP fusion has little effect $(D$, compare $E, F)$.

mity of localization along the length of the ROS as the number of potential lipidation sites is increased from two to four (compare Figs. $5 E, 6 B, E$; and $5 F, 6 C, F)$.

In interpreting the subcellular localization data described above, we have tacitly assumed that transgene expression does not interfere with cell function or viability and, therefore, that any defects in subcellular localization are referable to the GFP construct. This assumption is supported by the apparently normal morphology of transgenic rods in all retinas examined and by the normal distribution of WGA staining, which primarily reflects the subcellular localization of rhodopsin. It is also supported by the consistency of the subcellular localization pattern of GFP among different transgenic tadpoles carrying the same transgene despite animal-to-animal variations in the level of GFP per cell. All of the experiments involving transgene expression in rod photoreceptors used a zebrafish rhodopsin promotor that drives transcription less efficiently than does the Xenopus rhodopsin promotor described by Knox et al. (1998) (our unpublished observations). Quantitation of retinal GFP content by immunoblotting, and rhodopsin content by Coomassie staining of OS protein shows a GFP:rhodopsin mole ratio of $\sim 1: 20$ in transgenic tadpoles with the highest levels of GFP (data not shown). In some cases, variagated expression results in as few as $50 \%$ of rods expressing the transgene, in which case the mole ratio in the expressing cells would be $\sim 1: 10$. This low level of GFP relative to rhodopsin suggests that the GFP fusion proteins are unlikely to saturate or interfere with the machinery for OS sorting and localization.

\section{Discussion}

The experiments reported here show that the C-terminal 16 amino acids of prRDH confer efficient OS localization on a linked GFP reporter. Because this C-terminal sequence functions in both rods and cones, it suggests that both types of photoreceptors use essentially the same recognition system for OS localization. The relevant features of this C-terminal region appear to be the three cysteines and the ... (V/I)XPX motif at the extreme $\mathrm{C}$ terminus. In the context of the GFP fusion proteins analyzed here, we have shown that the three cysteines mediate membrane association in both rod photoreceptors and 293 cells via palmitoylation. Furthermore, we have shown that a significant fraction of bovine prRDH can be released from its association with OS membranes by hydroxylamine treatment and that the $\mathrm{C}$ terminus of the released prRDH is immunochemically distinguishable from the membraneassociated prRDH in a manner consistent with hydroxylamine-dependent cleavage of a thioester adduct at the most C-terminal of the three cysteines. Taken together, these data imply that membrane association of native prRDH is mainly or entirely mediated by fatty acylation (most likely palmitoylation) of one or more C-terminal cysteines.

The ... (V/I)XPX motif at the extreme $\mathrm{C}$ terminus of prRDH appears to function as an OS localization signal. This function requires membrane association, which can be provided by $\mathrm{N}$ - or C-terminal lipidation sites. Whereas the ... (V/I)XPX sequence is required for efficient OS localization, less efficient OS localization can still be observed in its absence. These characteristics also hold for the extreme C-terminal ... VXPX of rhodopsin, as observed here and as reported by Sung et al. (1994) and Concepcion et al. (2003) in transgenic mice and by Tam et al. (2000) and Moritz et al. (2001) in transgenic Xenopus. The similarity between the amino acids at positions -4 and -2 in the $C$ termini of prRDH and vertebrate visual pigment sequences, the clustering of substitution mutations at the -4 and -2 positions in the rhodopsin gene in patients with autosomal dominant retinitis pigmentosa, and the similar activities of the rhodopsin and prRDH C termini in transgenic Xenopus strongly suggests that these two protein families share the same mechanism of OS localization and that this mechanism involves recognition of the -4 and -2 positions. Whether this motif can function at positions other than the extreme $\mathrm{C}$ terminus is unknown at present. For rhodopsin, one line of work on OS localization has focused on the binding of the $\mathrm{C}$ terminus to Tctex-1, a small ubiquitously expressed cytoplasmic dynein subunit that is proposed to target rhodopsin-containing vesicles within the IS (Tai et al., 1999). The possibility that the photoreceptor has additional proteins that bind to the ... VXPX motif remains to be determined.

On the assumption that rhodopsin and prRDH share a C-terminal OS localization motif, it is curious that this motif is not evident at the $\mathrm{C}$ termini of other OS proteins. (For this anal- 
ysis, we have examined arrestin, the three transducin subunits, the three cGMP phosphodiesterase subunits, the two cGMP-gated channel subunits, the $\mathrm{Na}$ / K/Ca exchanger, RGS9, R9AP, guanylate cyclases $2 \mathrm{D}$ and $2 \mathrm{~F}$, the guanylate cyclase activating protein, phosducin, and recoverin.) This observation suggests that multiple or degenerate recognition and localization mechanisms may be operating in photoreceptors. There are precedents in a number of other systems for this model. For example, among peroxisomal matrix proteins, import of the cytosolic precursor can be mediated by either a C-terminal motif, SKL, or an N-terminal motif, (R/ $\mathrm{K}) \mathrm{LXX}(\mathrm{Q} / \mathrm{H}) \mathrm{L}$ (Sacksteder and Gould, 2000). Perhaps more relevant to OS sorting are the highly degenerate recognition motifs used in endocytosis of receptors at the plasma membrane, import of cytosolic precursors into mitochondria, and cotranslational insertion of nascent proteins across the endoplasmic reticulum membrane. In the first case, one recognition motif in the cytoplasmic domain of the receptor consists of an adjacent pair of bulky hydrophobic amino acids, typically leucines (Heilker et al., 1999); in the second case, the motif consists of an N-terminal amphipathic helix rich in positively charged amino acids (Voos et al., 1999); and in the third case, it consists of an N-terminal hydrophobic region of 10-15 amino acids bounded by polar amino acids, charged amino acids, or both (Lingappa and Blobel, 1980). These precedents suggest that diverse OS proteins may share structure-based motifs that are not readily apparent from comparisons of primary sequence.

Membrane association is a common feature of OS proteins, and for cytoplasmic proteins it typically occurs via lipidation and electrostatic interactions with phospholipid headgroups or, indirectly, via binding to a membrane-associated protein. A partial list of lipidated OS proteins includes: the $\alpha$ and $\gamma$ subunits of transducin, the $\alpha$ and $\beta$ subunits of cGMP phosphodiesterase, recoverin, and, presumably, prRDH. Most previous analyses of the role of membrane association focused on the kinetic advantages for phototransduction of two-dimensional, rather than three-dimensional, diffusion of interacting proteins (Pugh and Lamb, 1993). The present observations, together with those of Tam et al. (2000), suggest that membrane tethering may also be required for a quite different reason: to facilitate OS localization. These observations also raise a new question: How are the many lipidated photoreceptor proteins that are not destined for the OS, such as small GTP-binding proteins, selectively excluded? The observation that a substantial fraction of a membrane-tethered GFP lacking a C-terminal OS localization signal localizes to the ROS suggest that a mechanism for active exclusion of untargeted photoreceptor proteins might be required to achieve the observed selectivity.

At what point in the OS targeting process does the C-terminal region of prRDH exert its function? Experiments with a wide variety of proteins, including neuronal proteins such as GAP43, PSD95, and SNAP25, implicate palmitoylation in selective target-
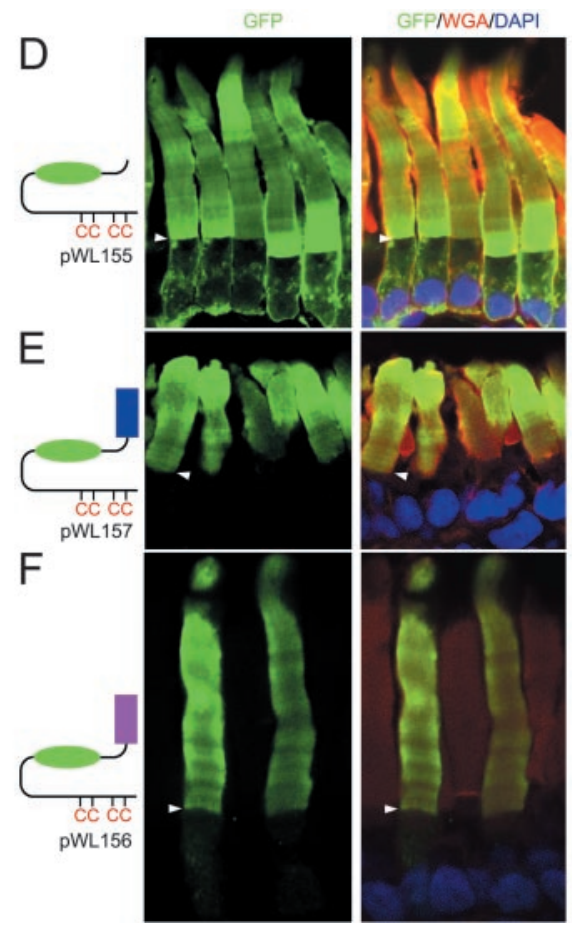

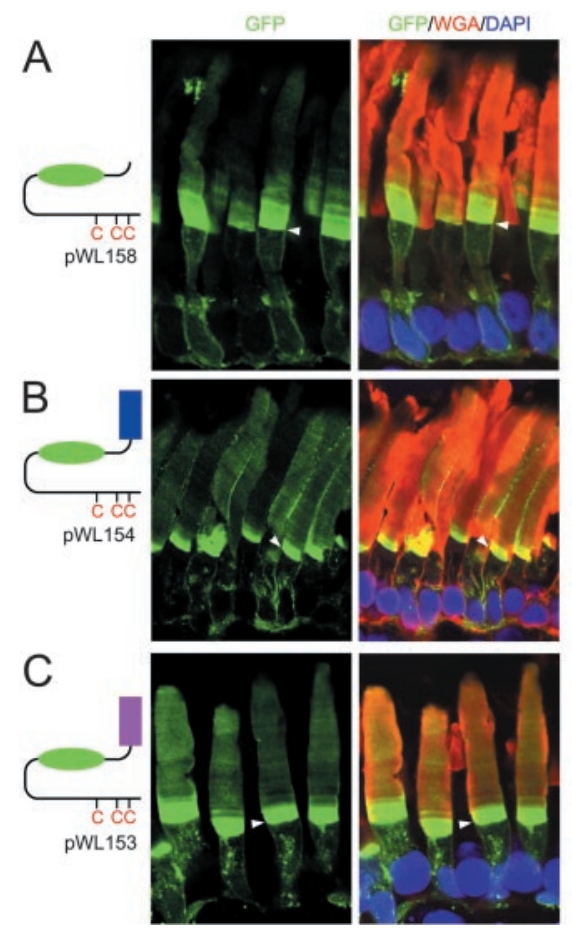

Figure 6. Additional palmitoylation sites increase ROS localization of GAP43-GFP fusion proteins with C-terminal ... (V/I)XPX motifs. A-C, An N-terminal extension derived from GAP43 and containing three palmitoylation sites (each represented by C) fused Fing the eight C-terminal amino acids from $\operatorname{prRDH}(E)$ or rhodopsin $(F)$. Highly efficient ROS localization is observed for the itoylation sites when the ... (V/I)XPX motif is added at the C terminus ( $D$, compare $E, F)$.

ing to subdomains of cellular membranes and, in particular, to the detergent-resistant subdomains referred to as lipid rafts (ElHusseini and Bredt, 2002). For GAP43 and PSD95, it appears that a combination of palmitoylation and the sequence of amino acids immediately adjacent to the palmitoylation site determine their selective sorting to axons versus dendrites, respectively (ElHusseini et al., 2001). In the photoreceptor, an association of the prRDH C terminus with lipid subdomains or subsets of vesicles could determine apical versus basolateral plasma membrane sorting or availability for transport along the connecting cilium, as has been suggested for the sorting of apical membrane and membrane-associated proteins in various polarized epithelia (Slimane and Hoekstra, 2002). In one variation on this theme, OS transport of proteins other than rhodopsin might occur via an association with rhodopsin (by far the most abundant OS protein) or rhodopsin-containing intracellular vesicles; in this model, the principal sorting signal would reside in rhodopsin. Under this model, prRDH, which carries its own C-terminal localization signal analogous to that carried by rhodopsin, would presumably not require an association with rhodopsin-laden vesicles for trafficking to the OS.

In the present study, we made the serendipitous observation that several GFP fusion proteins showed preferential localization to the base of the ROS. In these cases, ROS localization showed a graded distribution, with the most prominent basal localization occurring when the GFP fusion carried fewer potential lipidation sites. This spatial gradient is unlikely to arise from a non-uniform temporal pattern of expression because similar transgenic tadpoles synthesizing rhodopsin-GFP do not exhibit a gradient of GFP concentration along the OS (data not shown). As described by Moritz et al. (2001), the rhodopsin-GFP distribution provides 
a visual record of the temporal pattern of gene expression because once an ROS disc has pinched off from the plasma membrane, integral membrane proteins residing within it, such as rhodopsin-GFP, cannot exchange with other discs or with the plasma membrane.

One possible source of the non-uniform OS distribution of the peripheral membrane GFP fusion proteins could be slow depalmitoylation in the OS. If depalmitoylated GFP diffuses from the OS to the IS, this would lead to a steady-state distribution in which the GFP fusion proteins are selectively depleted from the distal OS. A second possible source of the non-uniform OS distribution could be the transport system that mediates rapid lightdependent IS-OS shuttling of arrestin and transducin (Broekhuyse et al., 1985; Brann and Cohen, 1987; Philp et al., 1987; Whelann and McGinnis, 1988; McGinnis et al., 2002; Sokolov et al., 2002; Mendez et al., 2003; Peterson et al., 2003). The graded distribution could be explained if this transport system propelled the GFP fusion proteins in the more distal region of the ROS toward the base but was unable to move them across the connecting cilium.

The selective localization of proteins to ciliary structures is likely to also be important in assembling and concentrating transduction proteins within olfactory neurons and in assembling the kinocilia of auditory and vestibular hair cells. Mutations in the genes that orchestrate ciliary protein localization would, therefore, be expected to produce visual, olfactory, or auditory defects. Although several genes encoding components of the photoreceptor connecting cilium have been identified and several are mutated in patients with retinitis pigmentosa (Gao et al., 2002; Liu et al., 2002, 2003; Pazour et al., 2002; Zhao et al., 2003), at present there is no evidence that the encoded proteins are directly involved in the recognition of OS proteins. This picture should become clearer as future analyses of OS localization lead to the definition of additional localization motifs, the protein components involved in their recognition, and their roles in retinal or other neuronal diseases.

\section{References}

Anant JS, Ong OC, Xie H, Clarke S, O’Brien PJ, Fung BK-K (1992) In vivo differential prenylation of retinal cyclic GMP phosphodiesterase catalytic subunits. J Biol Chem 267:687-690.

Blaner WS, Churchich JE (1980) The membrane bound retinol dehydrogenase from bovine rod outer segments. Biochem Biophys Res Commun 94:820-826.

Brann MR, Cohen LV (1987) Diurnal expression of transducin mRNA and translocation of transducin in rods of rat retina. Science 235:585-587.

Broekhuyse RM, Tolhuizen EF, Janssen AP, Winkens HJ (1985) Light induced shift and binding of S-antigen in retinal rods. Curr Eye Res 4:613-618.

Concepcion F, Mendez A, Chen J (2002) The carboxyl-terminal domain is essential for rhodopsin transport in rod photoreceptors. Vis Res 42:417-426.

Dryja TP, McGee TL, Hahn LB, Cowley GS, Olsson JE, Reichel E, Sandberg MA, Berson EL (1990) Mutations within the rhodopsin gene in patients with autosomal dominant retinitis pigmentosa. $N$ Engl J Med 323:1302-1307.

Dryja TP, Hahn LB, Cowley GS, McGee TL, Berson EL (1991) Mutation spectrum of the rhodopsin gene among patients with autosomal dominant retinitis pigmentosa. Proc Natl Acad Sci USA 88:9370-9374.

El-Husseini Ael-D, Craven SE, Brock SC, Bredt DS (2001) Polarized targeting of peripheral membrane proteins in neurons. J Biol Chem 276:44984-44992.

El-Husseini Ael-D, Bredt DS (2002) Protein palmitoylation: a regulator of neuronal development and function. Nat Rev Neurosci 3:791-802.

Gao J, Cheon K, Nusinowitz S, Liu Q, Bei D, Atkins K, Azimi A, Daiger SP, Farber DB, Heckenlively JR, Pierce EA, Sullivan LS, Zuo J (2002) Progressive photoreceptor degeneration, outer segment dysplasia, and rho- dopsin mislocalization in mice with targeted disruption of the retinitis pigmentosa-1 (Rp1) gene. Proc Natl Acad Sci USA 99:5698-5703.

Gonzalo S, Linder ME (1998) SNAP-25 palmitoylation and plasma membrane targeting require a functional secretory pathway. Mol Biol Cell 9:585-597.

Heilker R, Spiess M, Crottet P (1999) Recognition of sorting signals by clathrin adaptors. BioEssays 21:558-567.

Ishiguro S, Suzuki Y, Tamai M, Mizuno K (1991) Purification of retinol dehydrogenase from bovine retinal rod outer segments. J Biol Chem 266:15520-15524.

Jackson CS, Magee AI (2002) Analysis of protein acylation. In: Current protocols in protein science, Vol 2 (Coligan JE, Dunn BM, Ploegh HL, Speicher DW, Wingfield PT, eds), pp 14.2.1-14.2.9. New York: Wiley.

Knowles A, Dartnall HJA (1977) The photobiology of vision. New York: Academic.

Knox BE, Schlueter C, Sanger BM, Green CB, Besharse JC (1998) Transgene expression in Xenopus rods. FEBS Lett 423:117-121.

Kroll KK, Amaya E (1996) Transgenic Xenopus embryos from sperm nuclear transplantations reveal FGF signaling requirements during gastrulation. Development 122:3173-3183.

Li T, Snyder WK, Olsson JE, Dryja TP (1996) Transgenic mice carrying the dominant rhodopsin mutation P347S: evidence for defective vectorial transport of rhodopsin to the outer segments. Proc Natl Acad Sci USA 93:14176-14181.

Linder ME, Kleuss C, Mumby SM (1995) Palmitoylation of G-protein $\alpha$ subunits. Methods Enzymol 250:314-330.

Lingappa VR, Blobel G (1980) Early events in the biosynthesis of secretory and membrane proteins: the signal hypothesis. Recent Prog Horm Res 36:451-475.

Lion F, Rotmans JP, Daemen FJM, Bonting SL (1975) Stereospecificity of ocular retinol dehydrogenases and the visual cycle. Biochim Biophys Acta 384:283-292.

Liu Q, Zhou J, Daiger SP, Farber DB, Heckenlively JR, Smith JE, Sullivan LS, Zuo J, Milam AH, Pierce EA (2002) Identification and subcellular localization of the RP1 protein in human and mouse photoreceptors. Invest Ophthalmol Vis Sci 43:22-32.

Liu Q, Lyubarsky A, Skalet JH, Pugh Jr EN, Pierce EA (2003) RP1 is required for the correct stacking of outer segment discs. Invest Ophthalmol Vis Sci 44:4171-4183.

Macke JP, Hennessey JC, Nathans J (1995) Rhodopsin mutation proline347-to-alanine in a family with autosomal dominant retinitis pigmentosa indicates an important role for proline at position 347 . Hum Mol Genet 4:775-776.

McGinnis JF, Matsumoto B, Whelan JP, Cao W (2002) Cytoskeleton participation in subcellular trafficking of signal transduction proteins in rod photoreceptor cells. J Neurosci Res 67:290-297.

Mendez A, Lem J, Simon M, Chen J (2003) Light-dependent translocation of arrestin in the absence of rhodopsin phosphorylation and transducin signaling. J Neurosci 23:3124-3129.

Molday RS (1998) Photoreceptor membrane proteins, phototransduction, and retinal degenerative diseases. Invest Ophthalmol Vis Sci 39:2491-2513.

Moritz OL, Tam BM, Knox BE, Papermaster DS (1999) Fluorescent photoreceptors of transgenic Xenopus laevis imaged in vivo by two microscopy techniques. Invest Ophthalmol Vis Sci 40:3276-3280.

Moritz OL, Tam BM, Papermaster DS, Nakayama T (2001) A functional rhodopsin-green fluorescent protein fusion protein localizes correctly in transgenic Xenopus laevis retinal rods and is expressed in a timedependent pattern. J Biol Chem 276:28242-28251.

Nicotra C, Livrea MA (1982) Retinol dehydrogenase from bovine retinal rod outer segments. Kinetic mechanism of the solubilized enzyme. J Biol Chem 257:11836-11841.

Palczewski K, Jager S, Buczylko J, Crouch RK, Bredberg DL, Hofmann KP, Asson-Batres MA, Saari JC (1994) Rod outer segment retinol dehydrogenase: substrate specificity and role in phototransduction. Biochemistry 33:13741-13750.

Papermaster DS (1982) Preparation of retinal rod outer segments. Methods Enzymol 81:48-52.

Pazour GJ, Baker SA, Deane JA, Cole DG, Dickert BL, Rosenbaum JL, Witman GB, Besharse JC (2002) The intraflagellar transport protein, IFT88, is essential for vertebrate photoreceptor assembly and maintenance. J Cell Biol 157:103-113. 
Peterson JJ, Tam BM, Moritz OL, Shelamer CL, Dugger DR, McDowell JH, Hargrave PA, Papermaster DS, Smith WC (2003) Arrestin migrates in photoreceptors in response to light: a study of arrestin localization using an arrestin-GFP fusion protein in transgenic frogs. Exp Eye Res 76:553-563.

Philp NJ, Chang W, Long K (1987) Light-stimulated protein movement in rod photoreceptor cells of the rat retina. FEBS Lett 225:127-132.

Pugh Jr EN, Lamb TD (1993) Amplification and kinetics of the activation steps in phototransduction. Biochim Biophys Acta 1141:111-149.

Qin N, Pittler SJ, Baehr W (1992) In vitro isoprenylation and membrane association of mouse rod photoreceptor cGMP phosphodiesterase alpha and beta subunits expressed in bacteria. J Biol Chem 267:8458-8463.

Rattner A, Smallwood PM, Nathans J (2000) Identification and characterization of all-trans-retinol dehydrogenase from photoreceptor outer segments, the visual cycle enzyme that reduces all-trans-retinal to all-transretinol. J Biol Chem 275:11034-11043.

Reiss Y, Goldstein JL, Seabra MC, Casey PJ, Brown MS (1990) Inhibition of purified p21ras farnesyl:protein transferase by Cys-AAX tetrapeptides. Cell 62:81-88.

Resh MD (1999) Fatty acylation of proteins: new insights into membrane targeting of myristoylated and palmitoylated proteins. Biochim Biophys Acta 1451:1-16.

Rosas DJ, Roman AJ, Weissbrod P, Macke JP, Nathans J (1994) Autosomal dominant retinitis pigmentosa in a large family: a clinical and molecular genetic study. Invest Ophthalmol Vis Sci 35:3134-3144.

Sacksteder KA, Gould SJ (2000) The genetics of peroxisome biogenesis. Annu Rev Genet 34:623-652.

Sawicki MW, Erman M, Puranen T, Vihko P, Ghosh zens(1999) Structure of the ternary complex of human 17beta-hydroxysteroid dehydrogenase type 1 with 3-hydroxyestra-1,3,5,7-tetraen-17-one (equilin) and NADP +. Proc Natl Acad Sci USA 96:840-845.

Slimane TA, Hoekstra D (2002) Sphingolipid trafficking and protein sorting in epithelial cells. FEBS Lett 529:54-59.

Sokolov M, Lyubarsky AL, Strissel KJ, Savchenko AB, Govardovskii VI, Pugh Jr EN, Arshavsky VY (2002) Massive light-driven translocation of trans- ducin between the two major compartments of rod cells: a novel mechanism of light adaptation. Neuron 34:95-106.

Srinivasa SP, Bernstein LS, Blumer KJ, Linder ME (1998) Plasma membrane localization is required for RGS4 function in Saccharomyces cerevisiae. Proc Natl Acad Sci USA 95:5584-5589.

Sung CH, Davenport CM, Hennessey JC, Maumenee IH, Jacobson SG, Heckenlively JR, Nowakowski R, Fishman G, Gouras P, Nathans J (1991) Rhodopsin mutations in autosomal dominant retinitis pigmentosa. Proc Natl Acad Sci USA 88:6481-6485.

Sung CH, Makino C, Baylor D, Nathans J (1994) A rhodopsin gene mutation responsible for autosomal dominant retinitis pigmentosa results in a protein that is defective in localization to the photoreceptor outer segment. J Neurosci 14:5818-5833.

Tai AW, Chuang JZ, Bode C, Wolfrum U, Sung CH (1999) Rhodopsin's carboxy-terminal cytoplasmic tail acts as a membrane receptor for cytoplasmic dynein by binding to the dynein light chain Tctex-1. Cell 97:877-887.

Tam BM, Moritz OL, Hurd LB, Papermaster DS (2000) Identification of an outer segment targeting signal in the $\mathrm{COOH}$ terminus of rhodopsin using transgenic Xenopus laevis. J Cell Biol 151:1369-1380.

Voos W, Martin H, Krimmer T, Pfanner N (1999) Mechanisms of protein translocation into mitochondria. Biochim Biophys Acta 1422:235-254.

Wald G, Hubbard R (1949) The reduction of retinene-1 to vitamin A-1 in vitro. J Gen Physiol 32:367-389.

Whelan JP, McGinnis JF (1988) Light-dependent subcellular movement of photoreceptor proteins. J Neurosci Res 20:263-270.

Yokoyama S (2000) Molecular evolution of vertebrate visual pigments. Prog Retin Eye Res 19:385-419.

Young RW (1967) The renewal of photoreceptor cell outer segments. J Cell Biol 33:61-72.

Zhao Y, Hong DH, Pawlyk B, Yue G, Adamian M, Grynberg M, Godzik A, Li $\mathrm{T}$ (2003) The retinitis pigmentosa GTPase regulator (RPGR)interacting protein: subserving RPGR function and participating in disk morphogenesis. Proc Natl Acad Sci USA 100:3965-3970. 